\title{
Mediating role of emotion regulation processes in the relationship between cognitive flexibility and intolerance to uncertainty
}

\author{
Zeynep Akkuş Çutuk * \\ Department of Educational Sciences, Trakya University, Turkey
}

\begin{abstract}
This study aims to examine whether emotional regulation processes play a mediating role in the relationship between cognitive flexibility and intolerance to uncertainty among university students. The sample consisted of 378 participants aged from 18 to 45 years. Data were obtained using the Cognitive Flexibility Inventory (CFI), Intolerance of Uncertainty Scale (IUS), and Emotion Regulation Processes Scale (ERPS). Structural Equation Modeling (SEM) was used to analyze the data. According to the results obtained from the research, emotion regulation processes have a partial mediating role in the relationship between cognitive flexibility and intolerance to uncertainty. The bootstrapping process also provided additional evidence that this partial mediation was significant. As a result, low cognitive flexibility negatively affects emotion regulation processes, resulting in low tolerance for uncertain situations.
\end{abstract}

Keywords: cognitive flexibility; intolerance to uncertainty; emotion regulation process

\section{Introduction}

Many definitions of cognitive flexibility (CF) have been made because of its complex structure and the interaction of various processes. It is seen that definitions such as the ability to change the cognitions according to changing environmental conditions (Crone, Ridderinkhof, Worm, Somsen, \& van der Molen, 2004; Dennis, \& Vander Wal, 2009; Stevens, 2009); competence belief in adapting to different options (Bilgin, 2009; Maltby, Day, McClutcheon, Martin \& Cayanus, 2004; Martin \& Rubin, 1995); interaction of multiple mechanisms to respond to multiple requests (Barbey, Colom, \& Grafman, 2013; Ionescu, 2012); ability to produce alternative solutions (Maria, 2006; Silver, Hughes, Bornstein, \& Beversdorf, 2004); the specificity of human intelligence (Boroditsky, Neville, Karns, Markman, \& Spivey, 2010); a type of fluent intelligence (Beversdorf, Hughes, Steinberg, Lewis, \& Heilman, 1999); semantic relationship forming and arranging process (Stahl \& Pry, 2005) are made for cognitive flexibility.

$\mathrm{CF}$ plays a key role in the ability to adapt to constantly changing environments and has been associated with a variety of targeted behaviors such as creativity, problemsolving, multitasking, and decision making (Dajani \& Uddin, 2015; Ionescu, 2012; Rolls, 2000). People with this ability can substitute more balanced and harmonious thoughts rather than thoughts that are challenging and incompatible, produce alternatives, and evaluate difficult situations as more manageable. This concept is generally associated with depression (Deveney \& Deldin, 2006; Teasdale et al., 2001). Impairment in $\mathrm{CF}$ was observed among depressed individuals and those at risk of

* Corresponding author.

E-mail address: zeynepacutuk@trakya.edu.tr

DOI: $10.51865 / J E S P .2021 .2 .17$ 
disease (Hou, Sui, Song, \& Yuan, 2016; Murphy, Michael, \& Sahakian 2012; Snyder, 2012; Trivedi \& Greer, 2014). Stressful events play an important role in the emergence and persistence of depressive disorders (Hammen, 2005). Since cognitive dysfunction is often associated with depressive disease, various types of stress also affect cognitive functionality (Lupien, McEwen, Gunnar, \& Heim, 2009). When an accustomed situation or course changes and an unexpected situation occurs, an uncertain situation is experienced, and this uncertainty causes stress in the individual. This situation also determines to what extent the individual can show his cognitive skills. Individuals who can cope better with stress can use their CF skills better (Çuhadaroğlu, 2013). It has been demonstrated that CF is an important feature that helps individuals to deal with uncertain situations competently (Demirtaş \& Yıldız, 2019), and social and personal variables such as tolerance and acceptance of uncertainty are related to CF (Çuhadaroğlu, 2013). In stressful situations, CF decreases intolerance of uncertainty and perceived stress levels (Demirtaş \& Yıldız, 2019).

Intolerance of uncertainty (IU) has been defined as a predisposition to show negative emotional, cognitive, and behavioral negative reactions to uncertain situations and events (Dugas, Buhr, \& Ladouceur, 2004). It has been stated that the perceptions and interpretations of people with low IU have a negative bias, and therefore they are more prone to interpret uncertain situations as threats (Buhr, \& Dugas, 2002; Dugas et al., 2005). In addition, this may cause the person to feel overwhelmed and unable to actively activate himself to overcome these emotions (Dugas et al., 2005).

It is thought that showing low tolerance by the people when they encounter uncertain situations is caused by low emotion regulation (ER) ability (Abbate-Daga, Quaranta, Marzola, Amianto, \& Fassino, 2015). Lack of emotion identification can impair individuals' ability to read emotionally stressful and uncertain situations. As a result, when these people encounter uncertain situations, they can use strict and stereotypical behaviors as a strategy to avoid emotional processes. In other words, the high level of IU is related to one's ability to deal with emotional processes (AbbateDaga et al., 2015; Yıldız \& Güllü, 2019). There is a high level of a positive relationship between ER processes and IU (Carpenter \& Chung, 2011).

ER is the process of monitoring, evaluating, and changing the emotional responses of the person while achieving his goals. Emotion regulation, in its simplest form, is the effort that people make to manage the emotional state, and the main purpose of this regulation is to change emotional responses (Gross, 2002; Koole, 2010; Thompson, 1994). The ER process can increase, decrease, or sustain the emotion that the person feels. The ER process can take place either explicitly or implicitly (Gross \& Thompson, 2007). While it takes a conscious effort to initiate, execute and monitor emotions in open emotion regulation, the process occurs in implicit ER automatically, without insight and awareness (Robinson, Safer, Austin, \& Aktif, 2015). At the same time, the ER process is a multivariate process, and its emotional intensity can be changed by spreading over time. Depending on the purpose of the person, a person can decrease the emotion, intensify it, or make it continue as it is (Gross, 2002). According to Gross (1998), people increase or decrease positive and negative emotions or try to maintain that emotion. Therefore, it is argued that we should not separate ER processes as functional and non-functional. Depending on the individual's situation, the ER strategy that will remain in good condition may change. In other words, it is stated that a strategy that is functional in one situation may not be in another situation (Smith \& Kleinman, 1989).

Bar-Anan, Wilson, and Gilbert (2009) argue that uncertainty reinforces both positive and negative affect. People learn to predict and control their environment by collecting information. Therefore, reducing uncertainty gives people an adaptive advantage. While uncertainty in negative content is experienced as a deterrent, uncertainty in positive content is experienced as rewarding. This effect is explained by the fact that uncertainty may support attention and increase curiosity. This suggests 
that it will cause people to become more emotionally dependent on uncertain situations.

When analyzed within the framework of the cognitive model; Emotions appear to arise due to beliefs and cognitions related to that condition and stimulus rather than the situation and stimulus itself. Certain cognitions constitute certain emotions (Reuman, Jacoby, Fabricant, Herring \& Abramowitz, 2015). IU is seen as cognitive distortion that affects individuals' perceptions, inferences, and responses about uncertainty (Liao \& Wei, 2011). It is thought that increasing the level of intolerance of the individual will positively affect mental health (Ciarrochi, Said \& Deane, 2010). People who perceive uncertain situations as threatening develop their belief that they cannot cope with these situations (Reuman, Jacoby, Fabricant, Herring, \& Abramowitz, 2015). While it is perceived as a source of uncertainty, stress, and anxiety, especially for people with low tolerance to uncertainty, it creates a negative mood. These people interpret uncertainty as an inevitable, unbearable, and stressful situation (Liao \& Wei, 2011). In cases of uncertainty, people cannot be functional. In other words, IU is associated with the beliefs that individuals cannot cope with in cases of unpredictability and uncertainty (Reuman, Jacoby, Fabricant, Herring, \& Abramowitz, 2015).

$\mathrm{CF}$ and the processes underlying this ability (executive functions) have also been found to play an important role in ER (Gotlib \& Joormann, 2010; Hofmann, Sawyer, Fang, \& Asnaani, 2012). In addition to facilitating purposeful behavior, CF is also effective in emotion regulation, and this ability is impaired in mood and anxiety disorders (Gabrys, Tabri, Anisman, \& Matheson, 2018). The factors that are effective in the formation of adaptation problems and negative emotional responses of individuals are the inflexible cognitions (Canas, Quesada, Antoli, \& Fajardo, 2003).

It was determined that harmonious and inharmonious ER strategies directly affect cognitive flexibility. In other words, it can be stated that individuals who use harmonized ER strategies such as positive re-focus, plan-re-focus, positive reevaluation, and acceptance are cognitively more flexible. On the other hand, it can be seen that individuals who use incongruous ER strategies such as self-blame, blame others, disaster, and rumination show less CF (Küçüker, 2016). According to Gratz \& Roemer (2004), individuals can regulate their emotions in a healthy way, if they can show flexibility to decide which of the compatible and incompatible ER strategies to achieve their goals and if they do not display behaviors such as sticking to a particular emotion, and trying to change that emotion, or ignoring it. There are significant positive correlations between $\mathrm{CF}$ and ER strategies and life satisfaction, and a significant negative relationship was found between $\mathrm{CF}$ and incompatible ER strategies (Fu \& Chow, 2016; Küçüker, 2016; Koesten, Schrodt, \& Ford, 2009; Wang $\&$ Liu, 2013).

Within the framework of all these theoretical approaches, the following hypotheses (H) were formed: (H1) Cognitive flexibility is associated with intolerance to uncertainty and emotion regulation process. (H2) Emotion regulation process is positively associated with intolerance to uncertainty. (H3) Emotion regulation process mediates the relationship between cognitive flexibility and intolerance to uncertainty.

\section{Methodology}

\subsection{Participants}

The research was carried out with 378 voluntary participants between the ages of 18-45 who study at various departments and levels (associate degree, undergraduate and graduate) of universities (Trakya University and Nişantaşı University). 156 of the participants $(41.2 \%)$ are women and $222(58.7 \%)$ of them are men (Mean $=28.69$; SD $=2.90$ ). Participants were informed about the research and an explanation was given about how the questionnaires should be filled. 


\subsection{Instruments}

Cognitive Flexibility Inventory (CFI)

Developed by Dennis and Vander Wal (2010), CFI consists of 20 items and two sub-dimensions as alternatives and control. CFI is a 5-point Likert type (1 Not Available, 5 Fully Suitable) measurement tool. The increase in the score obtained from the CFI means that CFis also high. In the validity and reliability study of the original form of the scale, the Cronbach alpha value of the alternatives subscale was determined as .91, and the Cronbach alpha values of the control subscale as .86 in the first measurement and .84 in the last measurement. The validity and reliability study of adaptation to Turkish was done by Gülüm and Dağ (2012). The Cronbach alpha internal consistency coefficient of the Turkish form was found to be .90 , and the internal consistency coefficients of the alternatives and control sub-dimensions were .89 and .85 , respectively. In this study, the Cronbach alpha coefficient of the subdimensions of CFI was calculated as .84 (for the control sub-dimension) and .88 (for the alternate sub-dimension), and the total Cronbach's alpha internal consistency coefficient of the scale was .89 .

Intolerance of Uncertainty Scale (IUS)

The original form of IUS was developed by Freeston, Rhéaume, Letarte, Dugas \& Ladouceur (1994), and adapted to English by Buhr \& Dugas (2002) and adapted to Turkish by Sarı \& Dağ (2009). IUS consists of 27 items and has 4 sub-dimensions (uncertainty is stressful and sad, negative self-assessments of uncertainty, not knowing the future is uncomfortable, and uncertainty prevents action). The assessment of the scale is in a 5-point Likert type structure, ranging from 1 Never Defines Me, 5 Defines Me Exactly. As the scores obtained from the scale increase, IU decreases. Cronbach's alpha internal consistency coefficient of the English version of the scale was .94, and the reliability coefficient of the Turkish form was .93. It was found that the Cronbach alpha internal consistency coefficient of the IUS subdimensions varied between .74 and .81 in this study, and the reliability coefficient for the entire scale was .92.

Emotion Regulation Processes Scale (ERPS)

ERPS was developed by Schutte Manes, \& Malouff (2009), to measure the emotion regulation processes (1-environment/location selection, 2-changing environment/location, 3-distraction/diffusion of attention, 4-cognitive change, 5experiential response modulation 6-behavioral response modulation, 7-physical response modulation) suggested by John and Gross (2007). It is a 7-point Likert-type scale consisting of 28 items, and the first 16 items define antecedent-focused, and 12 items define response-oriented emotion regulation processes. High scores obtained from the scale indicate that it has high emotion regulation. In the original form of the scale, the reliability coefficient is .91 for the antecedent-focused ER processes and .85 for the response-focused ER processes. The scale was adapted to Turkish by Aka (2011). The total reliability coefficient of the scale was calculated as .91 .86 for antecedent-focused ER processes (first 16 items); and .83 for the response-focused ER processes (12 other items). In this study, Cronbach's alpha coefficient of the subdimensions of ERPS was calculated as .83 and .86 .

Personal Information Form

The Form, prepared by the researchers, consists of five questions about the participants' gender, age, university, department, and grade level.

\subsection{Data analysis}

Descriptive statistics and correlation analysis were performed first in this study, which was conducted to determine the network of relationships between cognitive flexibility (CF), intolerance of uncertainty (IU) and emotion regulation (ER) processes. Afterward, SEM was performed. SEM is a multivariate statistical method based on the definition of observable and unobservable variables in a causal and relational model based on a specific theory (Byrne, 2010). Since SEM includes a large 
number of statistics and takes into account more than one parameter in the decision stage, it is expressed as a very strong quantitative analysis (Kline, 2015). In this study, SEM was conducted in two stages according to the recommendations of Kline (2015) and Anderson and Gerbing (1988). The confirmatory measurement model is first tested in two-stage SEM, followed by testing the hypothetical structural model. The relationships between observed variables and the structure or structures that are assumed to be measured by these observed variables are tested in the measurement model (Wetson \& Gore, 2006). In the second stage of SEM, the structural model formed in line with theoretical inferences was tested. In the structural model, the paths established from the latent variables to the observed variables show the causal relationship between the two variables, and the significance of the paths and the goodness of fit of the model are examined (Schumacher \& Lomax, 2004). Various goodness of fit values is used to evaluate the model (Kline, 2015). It is put forward that acceptable goodness of fit indices of the values in question are $\leq 5$ for $\chi^{2} / \mathrm{sd}$; For Comparative Fit Index (CFI), Tucker-Lewis Index (TLI), Normed Fit Index (NFI) and Goodness of Fit Index (GFI) $\geq .90$, Standardized Root Mean Square Residuals (SRMR) and the Root Mean Square Error of Approximation (RMSEA) is suggested to be $\leq .08$ (Jöreskog \& Sörbom, 2004, Kline, 2015, Schumacker \& Lomax, 2004; Tabachnick \& Fidell, 2001).

The method of Baron and Kenny (1986) has been taken as a basis for testing both hypotheses and determining whether ER processes have an intermediary role in SEM. According to Baron and Kenny (1986), some conditions must be met in order to determine the mediation effect. First, CF should predict uncertainty. The second condition is that CF should have an effect on ER processes. Another condition is that ER processes should predict uncertainty. Finally, when ER processes are included in the equation, the decrease in the amount of relationship between $\mathrm{CF}$ and IU is partly considered as an indicator of mediation. The significance of the mediation effect was evaluated with the bootstrapping technique (5000 samples) and 95\% confidence intervals. In the mediation analysis made with the bootstrapping technique, in order to support the research hypothesis, the values within $95 \%$ confidence interval obtained as a result of the analysis should not include the zero value (Preacher \& Hayes, 2008). IBM SPSS Statistics 21.00 and IBM SPSS Amos 22.00 statistical package programs were used for the data analysis.

\section{Results}

\subsection{Descriptive Statistics and Correlation}

Before the descriptive statistics were calculated, whether the data obtained from the scales showed normal distribution was examined using skewness and kurtosis values. Accordingly, it was determined that the skewness value of Cognitive Flexibility Inventory (CFI) is -.14, the kurtosis value is .10; the skewness value of Intolerance of Uncertainty Scale (IUS) is .03, and the kurtosis value is -.17; the skewness value of Emotion Regulation Processes Scale (ERPS) is -.25 , and the kurtosis value is . 34 . The values obtained show that there is no significant problem in the normal distribution of the data obtained from the scales (George \& Mallery, 2010; Finney \& DiStefano, 2006; Huck, 2012; Kim, 2013). Descriptive statistics and correlation analysis results related to the scales are shown in Table 1.

Table 1. Descriptive statistics and correlation analysis results related to the scales

\begin{tabular}{ccccccc} 
& \multicolumn{3}{c}{ Correlation } & \multicolumn{3}{c}{ Descriptive Statistics } \\
\cline { 2 - 6 } & 1 & 2 & 3 & Mean (SD) & Skewness & Kurtosis \\
\hline 1. CFI & - & & & $78.44(9.80)$ & -.14 & .10
\end{tabular}




\begin{tabular}{|c|c|c|c|c|c|c|}
\hline 2. IUS & $-.43^{* *}$ & - & & $74.58(17.11)$ & .03 & -.17 \\
\hline 3. ERPS & $.38^{* *}$ & $.36^{* *}$ & - & $142.47(20.19)$ & -.25 & .34 \\
\hline
\end{tabular}

When Table 1 is examined, it is seen that all the variables in the research have significant relationships with each other. It was found that there was a negative and significant relationship between CFI and IUS $(\mathrm{r}=-.43, \mathrm{p}<.001)$ and a positive and significant relationship between CFI and ERPS $(r=.38, \mathrm{p}<.001)$. The relationship between IUS and ERPS was determined to be significant and positive $(r=.36$, $\mathrm{p}<.001)$.

\subsection{Structural Equation Modeling}

\subsubsection{Measurement Model}

The measurement model expresses the relevant indicators of latent variables or their relationship with the measured variables. It is recommended to test the measurement model before testing the structural model (Anderson \& Gerbing, 1988). Three latent variables were used in the structural equation model testing: $\mathrm{CF}$ (measured by the CFI), IU (measured by the IUS), and ER processes (measured by the ERPS). There are a total of 6 observed variables that make up these latent variables. The CF latency variables are the "alternatives" and "control" variables. The subdimensions of IUS, "the uncertainty is stressful and sad", "the negative selfevaluations about uncertainty", "not knowing the future," and "uncertainty prevents action" constitute IU latency variable. ER processes latent variable is constituted from, "antecedent-focused ER processes" and "response focused ER processes" observed variables which re sub-dimensions of ERPS.

As a result of the measurement model, it was determined that all path coefficients were significant and factor loads varied between .66 and .89. The measurement model appears to fit well and is confirmed $(\chi 2(38)=128.40, \chi 2 / \mathrm{df}=3.37, \mathrm{p}<.05 ; \mathrm{GFI}=.95$; $\mathrm{CFI}=.97 ; \mathrm{NFI}=.96 ; \mathrm{TLI}=.95 ; \mathrm{SRMR}=.059 ; \mathrm{RMSEA}=.072,90 \% \mathrm{CI}$ for $\mathrm{RMSEA}=$ $.048-.093)$.

\subsubsection{Structural Model}

In order to reveal the network of relationships between cognitive flexibility (CF), intolerance of uncertainty (IU) and emotion regulation (ER) processes, whether CF had a significant effect on IU was tested. Fit index values of the model tested in the research were determined as; $\chi 2(8)=28.95, \chi 2 / \mathrm{df}=3.61, \mathrm{p}<.05 ; \mathrm{GFI}=.96 ; \mathrm{CFI}=.98$; $\mathrm{NFI}=.97 ; \mathrm{TLI}=.95 ; \mathrm{SRMR}=.042 ; \mathrm{RMSEA}=.068,90 \% \mathrm{CI}$ for $\mathrm{RMSEA}=.030-.092$, and it showed that the model has a good fit. According to the findings, it is seen that $\mathrm{CF}$ has a negative significant effect on uncertainty $(\beta=-0.57 ; \mathrm{p}<0.05)$.

In the other model of the study, whether CF has a significant effect on ER processes, whether ER processes affect IU positively, and the mediating effect of ER processes on CF and IU were tested. In order to test these hypotheses, a separate model has been established in which ER processes are the mediators. As a result of the established model, it was determined that CF positively affects ER processes $(\beta=.48 ; p<0.05)$, and ER processes positively affect IU $(\beta=.45 ; p<0.05)$. However, it was observed that there was a decrease in the amount of relationship between $\mathrm{CF}$ and IU variable by including ER processes, which are mediating variables $(\beta=-.18$; $\mathrm{p}>0.05)$. Considering the goodness-of-fit indices of the model that ER processes are a partial tool, it was determined that all values were found to be acceptable $(\chi 2(39)=$ 130.36, $\chi 2 / \mathrm{sd}=3.34, \mathrm{p}<.05 ; \mathrm{GFI}=.94 ; \mathrm{CFI}=.97 ; \mathrm{NFI}=.96 ; \mathrm{TLI}=.95 ; \mathrm{SRMR}=.060$; RMSEA $=.073,90 \%$ CI for RMSEA $=.048-.093$ ). In Figure 1, the structural model where ER processes are a partial tool between CF and IU is presented. 


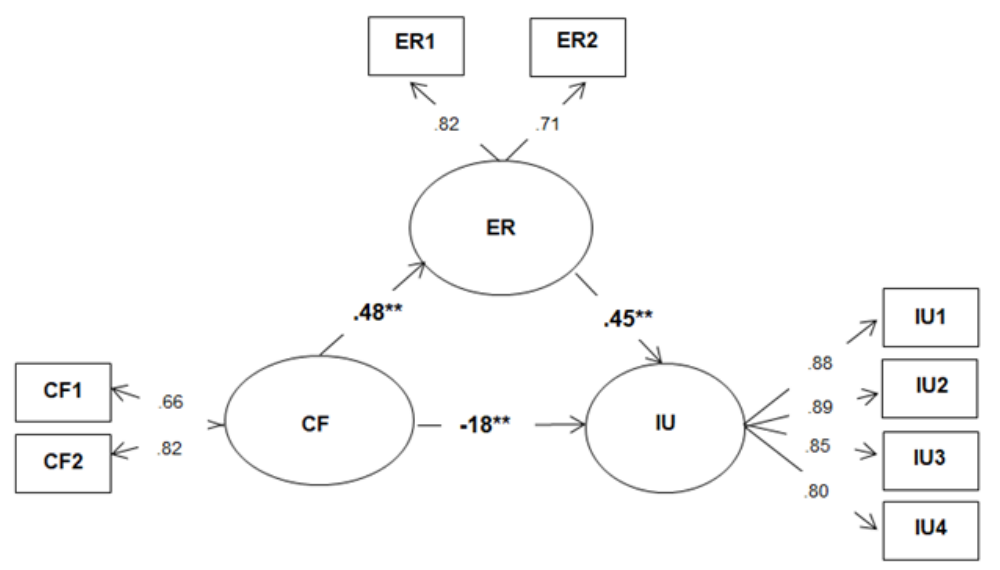

Figure 1. Partially Mediated Model

Note. $* *$ p<.05; CF1 alternatives, CF2 control, ER1 antecedent-focused ER processes, ER2 response-oriented ER processes, IU1 uncertainty is stressful and sad, IU2 negative self-assessments of uncertainty, IU3 not knowing the future is uncomfortable, IU4 uncertainty prevents action

\subsubsection{Bootstrapping Process}

The indirect effect was found to be significant according to the bootstrapping procedure performed to provide additional evidence whether the indirect effect in predicting the IU through emotional regulation processes of $\mathrm{CF}$ was significant $(\beta=0.24, \% 95 \mathrm{GA}=.14, .37)$. Bootstrapping lower and upper confidence interval values obtained by percentage method do not include zero value. According to all these results obtained, it can be said that ER processes are partially mediated in the relationship between $\mathrm{CF}$ and intolerance to ambiguity.

\section{Discussions}

In this study, the network of relations between cognitive flexibility (CF), intolerance to uncertainty (IU), and emotion regulation (ER) process among were examined, and it was concluded that ER processes were a partial mediator in the relationship between $\mathrm{CF}$ and IU.

The results of the model confirmed in the research are discussed in detail below. Firstly, it is discussed that CF affects IU positively. Studies on university students found that there was a significant negative relationship between $\mathrm{CF}$ and IU. Uncertainty is associated with intolerance, more hopelessness, and lower CF (Demirtaş \& Yıldız, 2019; Öztürk, 2013). Lieberman, Gorka, Sarapas, \& Shankman (2016) found that CF was negatively associated with IU in an adult sample diagnosed with panic disorder. IU is associated with the cognitive bias that affects people's perceptions, comments, and reactions to certain situations (Yook, Kim, Suh, \& Lee, 2010).

Another result obtained from the study is that CF affects ER processes positively. Murphy (2015) states that participants with low levels of depression use similar ER strategies and have a similar level of cognitive flexibility; participants who experienced high levels of depression were similar in ER and cognitive flexibility. In a study with clinical cases, internalized shame, emotional distress, and low CF were found to be associated with depression (Frost, 2012). 
Likewise, Rothermund, Voss, \& Wentura (2008) emphasized that individuals who cannot show flexibility in the cognitive part of ER develop resistance to change in their internal dynamics, and therefore they are unable to self-regulate and that they experience problems, show indecision, and postpone their actions, and he stated that they had a risk of depression and experienced adjustment problems. Biron, \& van Veldhoven, (2012) revealed that participants who showed psychological flexibility during the day were able to regulate their emotions in a healthier way and experience less emotional fatigue at the end of the day, in their study that they conducted on the employees in a workplace. From this point of view, they stated that their work is consistent with the findings that psychological flexibility is associated with ER and that individuals' acceptance as they are rather than trying to change or suppress their emotions, will bring them a less emotional burden, and flexibility plays an important role in this acceptance process (Küçüker, 2016).

It was found that there was a significant positive relationship between emotional intelligence and CF (Gündüz, 2013). A negative correlation was found between CF levels and emotional sensitivity, emotional reactivity, and psychological weakness levels (Yaşar Ekici, \& Balc1, 2019). As the level of CF of individuals increases, extraversion personality traits and self-control skills increase and become more open to development. On the other hand, it was concluded that as the CF level decreases, they become more emotionally inconsistent (neurotic) (Bilgin, 2017). Leahy, Tirch, \& Napolitano (2011) state that there is a significant relationship between psychological flexibility and emotional schemes, people who accept their feelings more, show less rumination, and who have more clear perceptions about the situation they are in, are psychologically more flexible.

Another finding obtained from the research is that ER processes positively affect IU. There is a high level of a positive correlation between ER processes and IU (Abbate-Daga et al., 2015; Carpenter \& Chung, 2011, Yüksel 2014). People who are intolerant of uncertainty can use strict and stereotypical behaviors as a strategy to avoid emotional processes when faced with uncertain situations. In other words, the high level of IU is related to one's ability to deal with the emotional process (AbbateDaga et al., 2015; Y1ldı, \& Güllü, 2019).

Moderate-large significant correlations between emotional regulation difficulties and IU were observed only in the clinical group (Bottesi, Tesine, Cerea, \& Ghisi, 2018). A positive correlation was found between IU and limited access to ER strategies (Ouellet, Langlois, Provencher, \& Gosselin, 2019). It was found that there was a negative relationship between IU and adaptive cognitive ER strategies and a positive relationship between IU and incompatible cognitive ER strategies. In addition, cognitive ER strategies have been found to play an intermediary role in the relationship between uncertainty and anxiety (Pourhosein, \& Hodhodi, 2016).

It was determined that there was a significant positive relationship between negative strategies of cognitive ER and IU (Alizadeh, Hasanzadeh, Mahmoud Alilou, \& Poursharifi, 2014). When evaluated in terms of ER skills, higher levels of ER skills in terms of both reducing negative emotions and positive rumination variables predicted an increase in the value of IU and a decrease in anxiety level. The increase in the decrease variable in positive emotion predicts both the level of IU and anxiety. Finally, it was observed that the increase in the value of IU predicted the increase in anxiety level (Yüksel, 2014).

A final finding in the model established in this research is that ER processes mediate the relationship between $\mathrm{CF}$ and IU. It has been found that there is a positive relationship between $\mathrm{CF}$ and ER, and harmonious ER strategies are effective in increasing individuals' CF (Küçüker, 2016). The factors that are effective in the formation of individuals' adaptation problems and negative emotional responses are inflexible cognitions (Canas, Quesada, Antoli, \& Fajardo, 2003). Individuals with low emotional regulation ability also show low tolerance when faced with uncertain situations (Abbate-Daga et al., 2015). It was determined that the occurrence of negative cognitive and emotional reactions related to emotions and IU was related (Dugas et al., 2005). These people perceive uncertain situations as threatening, which 
causes negative emotions and often causes anxiety (Dugas, Freeston, Blais, \& Ladouceur, 1994). In line with these results, it can be concluded that individuals with low CF experience difficulties in ER processes, and this situation also affects the level of people's IU, and individuals with the low emotional ability to show low tolerance in uncertain situations. In line with all the information obtained, it is thought that the model presented in the research is considered to be acceptable.

This research has limitation. The data received from the participants were obtained through self-reporting data collection tools. Therefore, the difficulties of self-reportbased measurements should not be ignored in the interpretation of the obtained findings.

\section{References}

1. Abbate-Daga G., Quaranta M., Marzola E., Amianto F., \& Fassino S. (2015). The relationship between alexithymia and intolerance of uncertainty in anorexia nervosa. Psychopathology, 48, 3, 202-208.

2. Aka, B. T. (2011). Perceived parenting styles, emotion recognition, and emotion regulation in relation to psychological well-being: Symptoms of depression, obsessive-compulsive disorder, and social anxiety. Unpublished Doctoral Dissertation, Orta Doğu Teknik University, Ankara.

3. Alizadeh, A., Hasanzadeh, L., Mahmoud Alilou, M., \& Poursharifi, H. (2014). Prediction of worry based on behavioral activation and inhibition systems (BAS/BIS), cognitive emotion regulation strategies and intolerance of uncertainty in students. Journal of Cognitive Psychology, 2(3).

4. Anderson, J. C., \& Gerbing, D. W. (1988). Structural equation modeling in practice: A review and recommended two-step approach. Psychological Bulletin, 103, 3, 411-423.

5. Barbey, A. K., Colom, R., \& Grafman, J. (2013). Architecture of cognitive flexibility revealed by lesion mapping. NeuroImage, 82, 547-554.

6. Bar-Anan, Y., Wilson, T. D., \& Gilbert, D. T. (2009). The feeling of uncertainty intensifies affective reactions. Emotion, 9, 1, 123-127.

7. Bardeen, J. R., Fergus, T. A., \& Orcutt, H. K. (2013). Testing a hierarchical model of distress tolerance. Journal of Psychopathology and Behavioral Assessment, 35, 4, 495-505.

8. Baron, R. M., \& Kenny, D. A. (1986). The moderator-mediator variable distinction in social psychological research: Conceptual, strategic, and statistical considerations. Journal of Personality and Social Psychology, 51, 6, 1173-1182.

9. Beversdorf, D. Q., Hughes, J. D., Steinberg, B. A., Lewis, L. D., \& Heilman, K. M. (1999). Noradrenergic modulation of cognitive flexibility in problem solving. NeuroReport, 10, 27632767.

10. Bilgin. M. (2009). Some variables predicting cognitive flexibility. Cukurova University Faculty of Education, 36, 3, 142-157

11. Biron, M., \& van Veldhoven, M. (2012). Emotional labour in service work: Psychological flexibility and emotion regulation. Human Relations, 65, 10, 1259-1282.

12. Boroditsky, L., Neville, H., Karns, C., Markman, A. B., \& Spivey, M. J. (2010). Flux: fundamental or frivolous? In S. Ohlsson, \& R. Catrambone (Eds.), Proceedings of the 32nd annual meeting of the cognitive science society (pp. 2918-2919) Austin, TX: Cognitive Science Society.

13. Bottesi, G., Tesini, V., Cerea, S., \& Ghisi, M. (2018). Are difficulties in emotion regulation and intolerance of uncertainty related to negative affect in Borderline Personality Disorder?. Clinical Psychologist, 22, 2, 137-147.

14. Buhr, K., \& Dugas M. J. (2002). The intolarence of uncertainty scale: psychometric \& properties of the English version. Behaviour Research and Therapy, 40, 8, 931-945.

15. Byrne, B. M. (2010). Structural equation modeling with amos. New York: Routledge.

16. Canas, J., Quesada, J., Antolí, A., \& Fajardo, I. (2003). Cognitive flexibility and adaptability to environmental changes in dynamic complex problem-solving tasks. Ergonomics, 46, 5, 482501.

17. Carpenter, L., \& Chung, M. C. (2011). Childhood trauma in obsessive compulsive disorder: The roles of alexithymia and attachment. Psychology and Psychotherapy: Theory, Research and Practice, 84, 4, 367-388. 
18. Ciarrochi, J., Said, T., \& Deane, F. P. (2005). When simplifying life is not so bad: The link between rigidity, stressful life events, and mental health in an undergraduate population. British Journal of Guidance \& Counselling, 33, 2, 185-197.

19. Crone, E. A., Ridderinkhof, K. R., Worm, M., Somsen, R. J. M. \& van der Molen, M. W. (2004). Switching between spatial stimulus-response mappings: A developmental study of cognitive flexibility. Developmental Science, 7, 4, 443-455.

20. Çuhadaroğlu, A. (2013). Predictors of cognitive flexibility. Cumhuriyet International of Education, 2, 1, 86-101.

21. Dajani, D. R., \& Uddin, L. Q. (2015). Demystifying cognitive flexibility: Implications for clinical and developmental neuroscience. Trends in Neurosciences, 38, 9, 571-578.

22. Dennis, J. P., \& Vander Wal, J. S. (2010). The cognitive flexibility inventory: Instrument development and estimates of reliability and validity. Cognitive Therapy and Research, 34, 3, 241-253.

23. Demirtaş, A.S., \& Yıldız, B. (2019). Hopelessness and perceived stress: The mediating role of cognitive flexibility and intolerance of uncertainty. The Journal of Psychiatry and Neurological Sciences, 3, 32, 259-267.

24. Deveney, C.M., \& Deldin, P.J. (2006). A preliminary investigation of cognitive flexibility for emotional information in major depressive disorder and non-psychiatric controls. Emotion, 6, 3, 429-437.

25. Dugas, M. J., Freeston, M. H., Blais, F., \& Ladouceur, R. (1994). Anxiety and depression in gad patients, high and moderate worriers. In Poster presented at the annual convention of the association for the advancement of behavior therapy. San Diego, CA.

26. Dugas, M. J., Hedayati, M., Karavidas, A., Buhr, K., Francis, K., \& Phillips, N.A. (2005). Intolerance of uncertainty and information processing: Evidence of biased recall and interpretations. Cognitive Therapy and Research, 29, 57-70.

27. Dugas, M. J., Buhr, K., \& Ladouceur, R. (2004). The Role of Intolerance of Uncertainty in Etiology and Maintenance. In R. G. Heimberg, C. L. Turk, \& D. S. Mennin (Eds.), Generalized anxiety disorder: Advances in research and practice (pp. 143-163). New York: Guilford Press.

28. Finney, S. J., \& DiStefano, C. (2006). Non-normal and categorical data in structural equation modeling. In Hancock, G. R., \& Mueller R. O. (Eds.), Structural equation modeling: A second course, (pp. 269-314). Information Age Publishing, U.S.A.

29. Freeston, M. H., Rhéaume, J., Letarte, H., Dugas, M. J., \& Ladouceur, R. (1994). Why do people worry?. Personality and Individual Differences, 17, 6, 791-802.

30. Frost, R. (2012). Depression in Psychosis: Associations with psychological flexibility and emotion regulation. Unpublished Doctoral Dissertation, University of Glasgow, England.

31. Gabrys, R.L., Tabri, N., Anisman, H., \& Matheson, K. (2018). Cognitive control and flexibility in the context of stress and depressive symptoms: The cognitive control and flexibility questionnaire. Frontiers in Psychology, 9, 2219.

32. George, D., \& Mallery, M. (2010). SPSS for Windows step by step: A simple guide and reference, 17.0 update (10a ed.) Boston: Pearson.

33. Gotlib, I. H., \& Joormann, J. (2010). Cognition and depression: Current status and future directions. Annual Review of Clinical Psychology, 6, 285-312.

34. Gratz, K. L., \& Roemer, L. (2004). Multidimensional assessment of emotion dysregulation: Development, factor structure, and initial validation of the Difficulties in Emotion Regulation Scale. Journal of Psychopathology and Behavioral Assessment, 26, 1, 41- 54.

35. Gross, J. J. (1998). Antecedent- and response-focused emotion regulation: Divergent consequences for experience, expression, and physiology. Journal of Personality and Social Psychology, 74, 1, 224-237.

36. Gross, J., \& Thompson, R. A. (2007). Emotion Regulation: Conceptual Foundations. Handbook of emotion regulation. New York. NY. US: Guilford Press, 3-24

37. Gross, J. J. (2002). Emotion regulation: Affective, cognitive, and social consequences. Psychophysiology, 39, 3, 281-291.

38. Gülüm, İ. V., \& Dağ, İ. (2012). The Turkish adaptation, validity and reliability study of the Repetitive Thinking Questionnaire and the Cognitive Flexibility Inventory. Anatolian Journal of Psychiatry, 13, 216-223.

39. Gündüz, B. (2013). Emotional intelligence, cognitive flexibility and psychological symptoms in pre-service teachers. Educational Research and Reviews, 8, 13, 1048-1056.

40. Hammen, C. (2005). Stress and depression. Annual Review of Clinical Psychology, 1, 293-319.

41. Huck, S. W. (2012). Reading statistics and research (6th ed). Boston: Pearson. 
42. Hou, Z., Sui, Y., Song, X., \& Yuan, Y. (2016). Disrupted interhemispheric synchrony in default mode network underlying the impairment of cognitive flexibility in late-onset depression. Frontiers in Aging Neuroscience, 8, 230.

43. Hofmann, S. G., Sawyer, A. T., Fang, A., \& Asnaani, A. (2012). Emotion dysregulation model of mood and anxiety disorders. Depression and Anxiety, 29, 5, 409-416.

44. Ionescu, T. (2012). Exploring the Nature of Cognitive Flexibility. New Ideas in Psychology, 30, 2, 190-200.

45. John, O. P., \& Gross, J. J. (2007). Individual Differences in Emotion Regulation. In J. J. Gross (Ed.), Handbook of emotion regulation (p. 351-372). The Guilford Press.

46. Jöreskog, K.G. \& Sörbom, D. (2004). LISREL 8.7 for Windows [Computer Software]. Lincolnwood, IL: Scientific Software International, Inc.

47. Fu, F., \& Chow, A. (2016). Traumatic exposure and psychological well-being: The moderating role of cognitive flexibility. Journal of Loss and Trauma, 22, 1, 24-35.

48. Kline, R. B. (2015). Principles and practice of structural equation modeling. New York: Guilford Press.

49. Kim, H. Y. (2013). Statistical notes for clinical researchers: assessing normal distribution (2) using skewness and kurtosis. Restorative Dentistry \& Endodontics, 38, 1, 52-54.

50. Koole, S. L. (2010). The psychology of emotion regulation: an integrative review. (In J. D. Houwerand ve D. Hermans (Eds), Cognition and emotion: reviews of current research and theories (ss.128-167). New York: Taylor \& Francis Group.

51. Koesten, J., Schrodt, P., \& Ford, D. J. (2009). Cognitive flexibility as a mediator of family communication environments and young adults' well-being. Health Communication, 24, 1, 8294.

52. Küçüker, D. (2016). The investigation of the relationships among forgiveness, unforgiveness, cognitive flexibility, emotion regulation and satisfaction with life. Unpublished Master's Dissertation. Pamukkale University, Denizli.

53. Leahy, R. L., Tirch, D., \& Napolitano L. A. (2011). Emotion regulation in psychotherapy, New York, Guilford Press.

54. Liao, K. Y., \& Wei, M. (2011). Intolerance of uncertainty, depression, and anxiety: the moderating and mediating roles of rumination. Journal of Clinical Psychology, 67, 12, 12201239.

55. Lieberman, L., Gorka, S.M., Sarapas, C., \& Shankman, S.A. (2016). Cognitive flexibility mediates the relation between intolerance of uncertainty and safety signal responding in those with panic disorder. Cognition and Emotion, 30, 8,1495-1503.

56. Lupien S. J., McEwen B. S., Gunnar M. R., \& Heim C. (2009). Effects of stress throughout the lifespan on the brain, behaviour and cognition. Nature Reviews Neuroscience, 10, 6, 434-45.

57. Maltby, J., Day, L., McCutcheon, L. E., Martin, M. M., \& Cayanus, J. L. (2004). Celebrity worship, cognitive flexibility and social complexity. Personality and Individual Differences, 37, 7, 1475-1482.

58. Maria, M. (2006). The Possible Relationship of Cognitive Style Rigidity-Flexibility of Cognitive Control with Properties of Nervous System. Procedia-Social and Behavioral Sciences, 82, 917-920.

59. Martin, M. M. \& Rubin, R. B. (1995). A new measure of cognitive flexibility. Psychological Reports, 76, 2, 623-626.

60. Murphy, J. W. (2015). Factors associated with emotion regulation flexibility. Unpublished Master's Dissertation. Illinois Institute of Technology, Chicago.

61. Murphy F. C., Michael A., \& Sahakian B. J. (2012). Emotion modulates cognitive flexibility in patients with major depression. Psychological Medicine, 42, 7, 1373-1382.

62. Ouellet, C., Langlois, F., Provencher, M.D., \& Gosselin, P. (2019). Intolerance of uncertainty and difficulties in emotion regulation: Proposal for an integrative model of generalized anxiety disorder. European Review of Applied Psychology, 69, 1, 9-18.

63. Özturk, O. (2013). Mediator role of cognitive flexibility and intolerance of uncertainty in relationship which between suicide probability and family functionality. Unpublished Master's Dissertation. Ankara University, Ankara.

64. Preacher, K. J., \& Hayes, A. F. (2008). Asymptotic and resampling strategies for assessing and comparing indirect effects in multiple mediator models. Behavior Research Methods, 40, 879891.

65. Pourhosein, R., \& Hodhodi, Z. (2016). Moderating effect of cognitive emotion regulation strategies on the relationship between intolerance of uncertainty and worry. Frooyesh, 4, 4, 6174. 
66. Reuman, L., Jacoby, R. J., Fabricant, L. E., Herring, B., \& Abramowitz, J. S. (2015). Uncertainty as an anxiety cue at high and low levels of threat. Journal of Behavior Therapy and Experimental Psychiatry, 47, 111-119.

67. Robinson, A., Safer, D. L., Austin, J. L., \& Etkin, A. (2015). Does implicit emotion regulation in binge eating disorder matter? Eating Behaviors, 18, 186-191.

68. Rolls E. T. (2000). Precis of the brain and emotion. Behavioral and Brain Sciences, 23, 2, 177 191.

69. Rothermund, K., Voss, A., \& Wentura, D. (2008). Counter-regulation in affective attentional biases: a basic mechanism that warrants flexibility in emotion and motivation. Emotion, 8, 1, 34-46.

70. Sarı, S., \& Dağ, D. (2009). Problem solving style, hopelessness, helplessness and haplessness as the predictors of psychopathology assessed by MMPI-2. Anatolian Journal of Psychiatry, 10, 261-270.

71. Schumacker, R. E., \& Lomax, R. G. (2004). A beginner's guide to structural equation modeling (2nd ed.). Mahwah, NJ: Lawrence Erlbaum.

72. Schutte, N. S., Manes, R. R., \& Malouff, J. M. (2009). Antecedent-focused emotion regulation, response modulation and well-being. Current Psychology: A Journal for Diverse Perspectives on Diverse Psychological Issues, 28, 1, 21-31.

73. Silver, J. A., Hughes, J. D., Bornstein, R. A., \& Beversdorf, D. (2004). Effect of anxiolytics on cognitive flexibility in problem solving. Cognitive Behavioral Neurology, 17, 2, 93-97.

74. Smith, A. C ve Kleinman, S. (1989). Managing emotions in medical school: Students' contacts with the living and the dead. Social Psychology Quarterly, 52, 1, 56-69.

75. Snyder H. R. (2012). Major depressive disorder is associated with broad impairments on neuropsychological measures of executive function: a meta-analysis and review. Psychological Bulletin, 139, 1, 81-132.

76. Stahl, L. \& Pry, E. (2005). Attentional flexibility and preseveration: Developmental aspects in young children. Child Neuropsychology, 11, 2, 175-189.

77. Stevens, A. D. (2009). Social Problem Solving and Cognitive Flexibility: Relations to Social Skills and Problem Behaviour of At-Risk Young Children. Unpublished Doctoral Dissertation, Seattle Pacific University, Washington.

78. Tabachnick, B.G., \& Fidell, L.S. (2001). Using Multivariate Statistics. 4th Edition, Allyn and Bacon, Boston.

79. Teasdale, J.D., Scott, J., Moore, R.G., Hayhurst, H., Pope, M., \& Paykel, E.S. (2001). How does cognitive therapy prevent relapse in residual depression? Evidence from a controlled trial. Journal of Consulting and Clinical Psychology, 69, 3, 347-357.

80. Thompson, R. A. (1994). Emotion regulation: A theme in search of definition. Monographs of the Society for Research in Child Development, 59, 2-3, 25-52, 250-283.

81. Trivedi M. H., \& Greer T. L. (2014). Cognitive dysfunction in unipolar depression: implications for treatment. Journal of Affective Disorders, 152-154, 19-27.

82. Wang, K., Liu, H. (2013). The relationship among cognitive flexibility,college students adaptability and affective well-being, Journal of Baoding University, 1, 110-114.

83. Weston, R., \& Gore, P. A. (2006). A brief guide to structural equation modeling. The Counseling Psychologist, 34, 5, 719-751.

84. Yaşar Ekici, F., \& Balcı S. (2019). Examination of the cognitive flexibility and emotional reactivity levels of preschool teacher candidates. Journal of Higher Education and Science, 9, 1, 65-77.

85. Yıldiz, B., \& Güllü, A. (2019). The mediator role of intolerance of uncertainty on the relationship between emotion regulation procesess and alexithymia. Electronic Journal of Social Sciences, 18, 69, 201-217.

86. Yüksel, B. (2014). Attachment, positive and negative emotion regulation, and intolerance of uncertainty in anxiety: Searching for an integrative model, Unpublished Master's Dissertation. Hacettepe University, Ankara.

87. Yook, K., Kim, K.H., Suh, S.Y., \& Lee, K.S. (2010). Intolerance of uncertainty, worry, and rumination in major depressive disorder and generalized anxiety disorder. Journal of Anxiety Disorders, 24, 6, 623-628. 